\title{
Practices and ethical concerns regarding preimplantation diagnosis. Who regulates preimplantation genetic diagnosis in Brazil?
}

\author{
B.B. Damian ${ }^{1}$, T.C.S. Bonetti ${ }^{2}$ and D.D.G. Horovitz ${ }^{1}$ \\ ${ }^{1}$ Centro de Genética Médica, Instituto Nacional de Saúde da Mulher, da Criança e do Adolescente Fernandes Figueira, \\ Fundação Oswaldo Cruz, Rio de Janeiro, RJ, Brasil \\ ${ }^{2}$ Departamento de Ginecologia, Universidade Federal de São Paulo, São Paulo, SP, Brasil
}

\begin{abstract}
Preimplantation genetic diagnosis (PGD) was originally developed to diagnose embryo-related genetic abnormalities for couples who present a high risk of a specific inherited disorder. Because this technology involves embryo selection, the medical, bioethical, and legal implications of the technique have been debated, particularly when it is used to select features that are not related to serious diseases. Although several initiatives have attempted to achieve regulatory harmonization, the diversity of healthcare services available and the presence of cultural differences have hampered attempts to achieve this goal. Thus, in different countries, the provision of PGD and regulatory frameworks reflect the perceptions of scientific groups, legislators, and society regarding this technology. In Brazil, several texts have been analyzed by the National Congress to regulate the use of assisted reproduction technologies. Legislative debates, however, are not conclusive, and limited information has been published on how PGD is specifically regulated. The country requires the development of new regulatory standards to ensure adequate access to this technology and to guarantee its safe practice. This study examined official documents published on PGD regulation in Brazil and demonstrated how little direct oversight of PGD currently exists. It provides relevant information to encourage reflection on a particular regulation model in a Brazilian context, and should serve as part of the basis to enable further reform of the clinical practice of PGD in the country.
\end{abstract}

Key words: Preimplantation genetic diagnosis; Public policy; Regulation; Ethics; Brazil

\section{Introduction}

Preimplantation genetic diagnosis (PGD) involves the genetic testing of embryos obtained through in vitro fertilization (IVF). It was originally developed as an alternative approach to prenatal diagnosis for couples who present a high risk of transmitting a genetic defect (1). The technique involves conducting genetic analyses on embryonic cells and then transferring the unaffected embryos into the uterus. Because this form of reproductive technology involves embryo selection, the medical, bioethical, and legal implications of the technique have been debated since its first application in 1989, particularly when it is used to select features that are not related to serious diseases (2-4). PGD has become a routine diagnostic procedure in the area of assisted reproduction, and countries have adopted very different legal approaches to its regulation, to the jurisdiction of authority, and to the nature of enforcement (1).
A milestone in international legislation occurred with the publication of the Warnock Report in the United Kingdom in 1984, which presents recommendations that are widely used as an international reference for the regulation of reproductive technologies (5). However, concerning PGD, complex issues related to ethics and equitable access to embryonic genetic testing have grown even more complicated and controversial in legislative debates. Although several initiatives have attempted to achieve regulatory harmonization across Europe and on other continents, a diversity of healthcare systems and the presence of cultural differences have hampered attempts to achieve this goal (2). Some initiatives of international organizations are relevant in this regard, such as the guidelines published by the European Society of Human Reproduction and Embryology (ESHRE). The ESHRE PGD Consortium not only reflects on the current use of PGD but also offers

Correspondence: Beatriz B. Damian: <bdamian@iff.fiocruz.br>; <beatrizdamian@uol.com.br>. 
consensus-based specific guidance regarding how best to practice clinical PGD based on clinical experience and data, both published and unpublished. The Consortium hopes that minimum standards of quality and safety might be achieved across all services actively providing clinical $P G D$, and recognizes that, owing to variations in local or national regulations and specific laboratory practices, there will remain differences in the ways in which PGD is practiced. However, this does not preclude a series of consensus opinions on best practices based on the available evidence $(6,7)$.

Political scientists, doctors, and bioethics experts have discussed the need for governments to improve the regulation of research into and clinical use of assisted reproduction technologies (ART) (5,8-11). Some argue for the adoption of new legislation to allow scientists to realize the potential benefits of reproductive technologies to human health. Others see legislation as necessary to prevent scientific exploration into areas that are ethically unacceptable. Some, of course, question the need for any government involvement. Knoppers et al. (2) highlighted the difficulties and limitations of establishing specific uses for PGD. For other political scientists, the practice of PGD depends not only on regulation itself but also on the structure of a country's healthcare system and social policy, ethical and scientific guidelines for selecting indications, and mechanisms and criteria for health insurance reimbursement $(11,12)$.

Thus, in each country, PGD is used with a specific approach that should reflect the views held by scientific groups, professional societies, legislators, and the society itself on the appropriate use of this technology. Although countries such as Austria and Germany have banned the use of PGD, others, such as Japan, Israel, Canada, and the United Kingdom, are discussing new uses for PGD and regulation strategies to maintain the method's reliability by defining standards and responsibilities for professionals performing $P G D$ and by protecting the rights of those concerned. In France and certain regions of Australia, India, and the Netherlands, regulations define the circumstances under which PGD is permissible. In other countries, such as the United States, there are no direct regulations for the technique, and, instead, professional guidelines for practicing service providers are consulted (2).

In Brazil, limited information has been published on PGD regulation, and no official organization regulates or systematically collects data on this practice. Hence, very little is known about the practice of PGD in Brazil. Although there have been some achievements in recent decades in the field of reproductive rights, issues such as those related to ART have been addressed timidly, especially in the context of hereditary genetic diseases. For regulation, the country relies on the use of various documents that are integral to the national agenda on reproductive health and human rights (13) but which are only loosely related to PGD. Since the late 1990s, several texts have been analyzed by the
National Congress to regulate the use of ART in the country. However, legislative debates remain inconclusive (14). Advancements of this technology in Brazil have increased State commitments to society, which involve the adoption of new regulatory standards and more ambitious policy goals that ensure access to this technology while guaranteeing its safe practice. Hence, an analysis of official documentation on $P G D$ regulation in Brazil was conducted to demonstrate how loosely this reproductive technology is regulated in this country. This study provided relevant information related to the public policy and legislative framework of PGD to encourage the introduction of a specific regulation model that promotes the adoption of PGD best practices in Brazil.

\section{Data collection}

Data for the analysis were drawn from official documents published by major regulatory organizations in Brazil that have worked in this field, from 1992 through August 2013. The period of study began in 1992 because the first official document on ART regulation in Brazil was published in that year by the Federal Council of Medicine [Conselho Federal de Medicina (CFM)]. Owing to the absence of specific regulation on $P G D$, the search for data on ART regulation in Brazil was extended, so that documentation that may contribute to PGD regulation was collected for analysis. The terms "assisted reproduction" ("reprodução assistida") or "human reproduction" ("reprodução humana") were used as search terms. Following criteria for authenticity and reliability, materials were surveyed in the National Public Archives in their printed (official publications) and digital (online) forms from the following Brazilian institutions: the National Press (http://www.in.gov.br), the House of Representatives (http://www.camara.leg.br), the Senate (http://www.senado.gov.br), the Ministry of Health (http:// portal.saude.gov.br), and the Federal Council of Medicine (http://www.portal.cfm.org.br). Twenty-two documents formed the final corpus of analysis as follows: one common law (Law 11.105/2005), eight bills (Bill 3638/1993, Bill 2855/ 1997, Bill 1135/2003, Bill 2061/2003, Bill 1184/2003 together with its 12 attachments, Bill 5624/2005, Bill 5730/2009, and Bill 4892/2012), one piece of Secretary of Health Care [Secretaria de Assistência à Saúde (SAS)] legislation (Ordinance 388/2005 SAS), four pieces of the Minister's Office [Gabinete do Ministro (GM)] legislation (Ordinance 426/2005 GM, Ordinance 1.187/2005 GM, Ordinance 2.048/ 2009 GM, and Ordinance 3.149/2012 GM), four pieces of Directors' Collegiate Resolution [Resolução da Diretoria Colegiada (RDC)] legislation (RDC 33/2006, RDC 29/2008, RDC 9/2011, and RDC 23/2011), and four CFM Resolutions (CFM 1358/1992, CFM 1931/2009, CFM 1957/2010, and CFM 2013/2013).

The selected content was organized and evaluated according to the content analysis approach presented by Bardin (15). For the initial stage of content analysis, the texts were carefully reviewed, and documents related to the fields 
of interest were selected. The material was subsequently categorized according to relevance and then grouped into two categories of ART access regulation in the context of hereditary genetic diseases, as provided in 1) public policies and 2) legislative frameworks.

\section{Results}

\section{Regulation of access to ART as provided in Brazilian public policies}

Issues related to reproductive technology access form an integral component of the public health agenda in Brazil in the area of reproductive rights, which is related to human rights and the right to health (13). Hence, to understand the current debates surrounding public policies in Brazil in this context, it is necessary to provide a brief analysis of reproductive rights in this country.

In Brazil, the principles of universality, equality, and equity are recognized as guiding principles that direct health services (16). Concerning the right to procreation, statements contend (Article 226, 7th paragraph of $\mathrm{CF} / 88$, and Organic Health Law 8.080/90) that family planning is both the citizen's right and a State responsibility, and that the Unified Health System [Sistema Unificado de Saúde (SUS)], on all levels, is obliged to ensure "assistance with conception and contraception" (Law 9.263/96) (17). However, the currently adopted approach that combines conception with reproductive health was only introduced in the country in 1984 through the Program for Integral Attention to Women's Health (Programa de Assistência Integral à Saúde da Mulher) (18), which was a milestone toward the goal of making the issue of reproductive health a health policy concern rather than one of population control.

During that same period, the issue of international reproductive rights was highlighted in the International Conference on Population and Development (CIPD; Cairo, 1994) and the IV World Conference on Women (Beijing, 1995), in which Brazil was an important participant. The establishment of the CIPD generated a movement away from the traditional focus on population growth and toward a discussion on strategies for promoting dignified lifestyles in various areas, including the realm of sexual and reproductive rights $(13,18)$

In this context, several legal approaches were created in Brazil from the 1990s, to legitimize the notion of sexual and reproductive rights. The Family Planning Law (Law 9.263/ 96), for instance, introduced normative views on reproductive rights to Brazil, related to such issues as contraception and conception assistance. The law defines family planning as the "set of actions regulating fertility and ensuring equal rights under the constitution for a limitation or increase in offspring by woman, man or couple" (17). However, despite the level of freedom ensured by this legislation, universal access has not been accomplished in reality, and, while public policy actions on ART have been developed (Table 1), they have also failed to ensure this right.

In 2004, the Health Ministry launched the National Policy on Sexual and Reproductive Rights (19) in response to social demand, international legal frameworks, and government precepts of the SUS. This approach culminated in the drafting of the National Policy for Integral Attention in Human Reproduction (Ordinance 426/2005 GM), which was recognized as a landmark public policy on conceptive care. In July 2005 , SAS Decree $388 / 2005$, which regulates the previous

Table 1. Public policies aimed at assisted reproduction techniques (ART) with respect to hereditary genetic diseases in Brazil.

Title/Date Comments

Nat. Policy Sexual and Reproductive Rights (Política Nac. Direitos Sexuais e Reprodutivos - MS; 2004)

Nat. Policy for Integral Attention in Human Reproduction (Política Nac. Atenção Integral em Reprodução Humana Assistida Ordinance 426/2005 GM)

Ordinance 388/2005 SAS

Ordinance $1.187 / 2005$ GM

Ordinance $2.048 / 2009 \mathrm{GM}$
Establishes guidelines to ensure sexual and reproductive rights, including attention to assisted reproduction in SUS.

Intended for infertile couples and those with infectious-contagious and genetic diseases, the establishment of a specific policy for assisted reproduction care at various levels of healthcare through SUS was a milestone in government policy concerning conception.

Gives the necessary support to organize and implement the State, City, and Federal District networks in Assisted Human Reproduction care.

Suspends previous ordinances for the analysis of the financial impacts and assessment of the Tripartite Inter-managers Committee.

Approves a new regulation in SUS for ART and revokes ordinance 426/2005 GM before its implementation under the justification of the need for an impact and financial resources assessment. Thus, there is no universal access in Brazil to the new reproductive technologies in SUS, violating the rights legitimized by the National Law.

GM: Gabinete do Ministro (Minister's Office); MS: Ministério da Saúde (Health Ministry); SAS: Secretaria de Assistência à Saúde (Secretary of Health Care); SUS: Sistema Único de Saúde (Unified Health System). 
ordinance and provides organizational and logistical support to state, city, and Federal District networks, was issued. However, the decree was later considered ineffectual and was revoked by Ordinance 1.187/2005 GM.

In 2009, Ordinance 2.048/2009 GM (Chapter II, Section II, Subsection IV, Articles 305-310) was issued, revoking Ordinance 426/2005 GM and replacing the National Policy for Integral Attention in Human Reproduction in the government agenda. This ordinance introduced a new approach to ART regulation in the SUS that was targeted to infertile couples and those who might benefit from vertical or horizontal transmission disease control, including the control of infectious-contagious and hereditary genetic diseases.

Also in 2009, several advances were made in the area of clinical genetics with the institution of the SUS National Policy for Integral Attention in Clinical Genetics (Ordinance $81 / 2009$ SAS) (20); however, this policy has not yet been implemented. The ordinance highlighted the importance of genetic counseling as the major healthcare service of clinical genetics and stressed that congenital abnormalities and genetically determined diseases are more prevalent in developing countries, possibly as a result of a lack of proper preventive care and therapeutic services.

Despite the indisputable progress of these public policies and stated goals, these projects have faced numerous challenges in their implementation. These challenges are largely attributable to resource shortages, limited coverage, a lack of qualifications, unequal access to reproductive health services, limited awareness, noncompliance with laws, and difficulty integrating management structures across several public administration spheres of the decentralized health system (21). Such challenges are commonly found in other developing countries, and it is evident that, in the face of numerous obstacles and demands, the government actions to secure these rights in Brazil have not been forthcoming until recently.

Although the National Policy for Integral Attention in Human Reproduction regulates ART in the SUS, this legislation does not fully ensure access rights. According to recent research conducted by Makuch et al. $(22,23)$, only five services provided through the public system offer ART, and those services are provided under limited circumstances and with no reference to PGD practice. The study demonstrated that a lack of ART at the state and city levels is typically attributable to a "lack of government will to implement it", followed by a "shortage of human and financial resources" (22). This lack of government commitment results in unequal access to this service among low-income couples (24), and the exclusion of this group from reproductive rights provided by law.

\section{Regulation of ART within the Brazilian legislative frameworks}

To understand the nature of PGD regulation in Brazil, one must review the progression of $A R T$ regulation that began in 1992, almost 10 years after the first IVF in the country. Regulation was first introduced with the adoption of Resolution CFM 1358/1992, issued by the CFM, the most prominent institution for the control of medical practices in the country. A hybrid collection of professional and bioethical standards, the resolution establishes guidelines on the use of ART and has remained, until recently, the only directive on professional services in this field. From the late 1990s, reproductive rights were introduced as part of the country's health policy agenda, and several bills and other legislative proposals have been analyzed by the National Congress to regulate the practice of ART. Legislative debates, however, have not been conclusive (Table 2) (14).

The first bill (Bill 3638/1993) and the other subsequent bills (Bill 2855/1997, Bill 1135/2003, and Bill 2061/2003) in this field make little mention of embryonic diagnostic techniques and merely reproduce the CFM resolution. In 2003 , Bill $1184 / 2003$ was approved by all Committees of the Senate and was presented to the Federal Chamber, suggesting the imminent adoption of an ART law into Brazilian legislation. However, the bill continues to await assessment by the Committee on the Constitution, Justice, and Citizenship. The spectrum of problems addressed in the first eight chapters of this bill was very broad, regulating, among other things, the use of ART for the prevention of hereditary genetic diseases. Changes made to the bill text throughout its evaluation led experts to consider the bill exceedingly controlling. There are 12 attachments to the bill (Bill 120/2003, Bill 4686/2004, Bill 1135/2003, Bill 2061/ 2003, Bill 4889/2005, Bill 4664/2001, Bill 6296/2002, Bill 5624/2005, Bill 3067/2008, Bill 7701/2010, Bill 3977/2012, and Bill 4892/2012), but none specifically discuss PGD.

In 2005, the drafting of the National Policy for Integral Attention in Human Reproduction (Ordinance 426/2005 GM) by the Ministry of Health highlighted Bill 5624/2005 that was instated, which addresses access to ART technology in the SUS and establishes a program that provides ART access to individuals with infertility or genetic and infectiouscontagious diseases. Regarding access to ART within the private healthcare system, Bill 5730/2009 proposes that ART be included as a private healthcare procedure that is covered by insurance, but is still awaiting approval.

In an effort to ensure ART access, Federal Law 11.935 (20), in force since 2009, obliged private healthcare insurance companies to ensure ART coverage based on the Family Planning Law. However, subsequently, the National Agency for Supplementary Health (Agência Nacional de Saúde Complementar) through the Normative Resolution [Resolução Normativa (RN)] 211/2010 (25) excluded ART from the list of procedures covered by healthcare insurance. Thus far, there is no coverage for ART by health insurance companies in Brazil, which is included in PGD. Nevertheless, discussions surrounding the legitimacy of this coverage, especially with respect to PGD for medical conditions, spurred new lawsuits based on pre-established reproductive rights. 
Table 2. Major legislation and other proposals aimed at assisted reproduction techniques (ART) in the context of hereditary genetic diseases in Brazil.

\begin{tabular}{ll}
\hline Title/Date & Comments \\
\hline CFM 1358/1992 & Adopts ethical standards for the use of ART, such as deontological devices, to be followed by doctors. \\
Bill 3638/1993 & $\begin{array}{l}\text { First bill of the legislature on the theme. The bill was considered a transposition of CFM 1358/1992, mistakenly } \\
\text { maintaining the perception that the discussion was about a purely technical issue for reproductive medicine, } \\
\text { thereby resulting in an indifferent legislative debate for a decade despite the other bills that followed during that } \\
\text { period. }\end{array}$
\end{tabular}

Bill $1184 / 2003$

Approved by the Federal Senate, this bill provides guidelines for the use of ART in cases of infertility and the prevention of genetic diseases linked to sex or in cases of medical indications, considering other treatment options available, such as hereditary genetic diseases. Currently, there are 12 appendices in the House of Representatives, indicating that the legislative process will be jointly held and awaits approval.

Bill 5624/2005 Creates the Program for Assisted Reproduction in the SUS and provides other measures. Its goal, among others, is to offer ART for people with genetic diseases. It is appended to Bill 5624/2005.

$\operatorname{RDC} 33 / 2006$ and RDC 29/2008

Bill 5730/2009

CFM 1931/2009

$\operatorname{RDC} 9 / 2011$ and RDC 23/2011

CFM $1957 / 2010$

Bill 4892/2012

CFM 2013/2013
Establishes the technical regulation for the operation of the Bank of Germ Cells and the sending of information on human embryos created by IVF (SisEmbrio) to monitor this activity and produce compilation of national data.

Amendment to Law 9656/1998, which "refers to private healthcare insurance" and determines the inclusion of assisted reproduction among the services offered by health insurances. Appended to Bill 4076/2001.

Establishes good medical practice with respect to the use of ART, and establishes guidelines for the use of embryonic cells and gene therapies (articles 14, 15 and 16).

Refers to the operation of Cell Technology Centers for the purpose of clinical research and therapy and provides other measures.

Repeals the old resolution CFM 1358/1992 and refers to ethical guidelines for professionals and services of ART. Refers to embryonic genetic testing for selecting sex with medical indications and in the prevention of hereditary genetic disorders.

Establishes the Statute for Assisted Reproduction to regulate the implementation and use of ART and its effects in the context of social civil relationships. Appended to Bill 1184/2003.

Confirms the use of PGD to avoid diseases related to the sex of the child and refers to its use for the diagnosis of disease-causing genetic alterations and for the selection of embryos by histocompatibility.

SUS: Sistema Único de Saúde (Unified Health System); IVF: in vitro fertilization; CFM: Conselho Federal de Medicina (Federal Council of Medicine); PGD: preimplantation genetic diagnosis. RDC: Resolução da Diretoria Colegiada (Directors' Collegiate Resolution).

Concerning control over ART clinics in the country, progress was achieved in 2005 with the implementation of the Law of Biosafety (Law 11.105/2005), which provides guidelines on the use of embryonic stem cells produced via IVF for research and therapy purposes in Brazil. In 2006, the National Health Surveillance Agency (Agência Nacional de Vigilância Sanitária) approved the technical regulation of Banks of Germ Cells and Tissues [Banco de Celulas e Tecidos Germinativos (BCTG)] with RDC 33/2006 and RDC $29 / 2008$. The latter resulted in the creation of the National System for the Production of Embryos (Sistema Nacional de Produção de Embriões or SisEmbrio), which aims to create a database of the number of embryos stored in the BCTG. Subsequently, with the induction of RDC 9/2011 and RDC 23/2011, this body was assigned the responsibility to regulate this operation. These resolutions do not explore the regulation of ART clinics for PGD and do not provide guidelines for best practices of this technique. Thus, they perpetuate autonomy for services and professionals in Brazil, which may be detrimental to the safety and efficacy of PGD in the country.

Considering that there was a lack of regulation of many aspects of ART, the CFM addressed ART nearly two decades after Resolution CFM 1358/1992. The CFM proposed a new Code of Medical Ethics (CFM 1931/2009), in which Articles 14, 15, and 16 discuss human reproduction. With respect to the use of embryonic cells, Article 15, Paragraph 2 prohibits physicians from creating genetically modified humans or embryos for research purposes, sex selection, eugenics, or the generation of hybrids or chimeras. 
Paragraph 3 reinforces the importance of clarification and agreement between involved parties prior to procedure execution. Article 16 notes that, regarding the "application of knowledge generated from new technologies, considering its impact both in the present and on future generations, the physician must ensure that individuals are not discriminated against based on genetic inheritance, thus protecting their dignity, identity and integrity".

In 2010, in response to the complicated nature of these issues, the progression of technical scientific advances, and ethical dilemmas, the CFM conducted a review of Resolution CFM 1358/1992. In doing so, the CFM convened representatives of the Brazilian Society of Human Reproduction and Brazilian Federation of Gynecology and Obstetrics Societies to create Resolution CFM 1957/2010, providing an important space for debate on this issue in Brazil. The resolution provides new ethical directives on ART professional services and revokes the now redundant Resolution CFM 1358/1992.

In 2010, the first direct reference to PGD was made, establishing guidelines on sex selection, genetic testing for medical conditions, and the prevention of hereditary genetic diseases. General reference was made to controversial issues such as those related to safety, efficacy, and legal ethical aspects of PGD. In this way, clinical and professional practitioners in Brazil were able to maintain their autonomy. Article 1 Paragraph 4 states that ART "must not be applied for the purposes of sex selection (sexing) or to affect any other biological trait of a future child with the exception of cases involving gender-related disease prevention". Article 6 , which refers to the diagnosis and treatment of embryos, notes that ART may be used to prevent or treat hereditary or genetic diseases "with sufficient certainty of a positive diagnosis and therapeutic outcome and with the informed consent of the couple". Paragraph 1 states that in vitro intervention on embryos conducted for diagnosis purposes may only be carried out to evaluate its viability or to detect hereditary diseases. With respect to in vitro interventions on embryos for therapeutic purposes, Paragraph 2 states that "it must have no other purpose other than to treat a disease or prevent its transmission, and it must be conducted based on a firm guarantee of success".

In 2012, new bills reflected consensus agreements reached between professional societies in this area of legislation. Of note is Bill 4892/2012, which established the Assisted Reproduction Statute and which is still awaiting consideration by the Plenary. Specific reference to PGD in Chapter I, Article 4, largely reproduces guidelines presented in Resolution CFM 1957/10. Article 5 adds that "medical techniques of reproductive treatment may also be applied to prevent the transmission of diseases that are considered dangerous to the child".

On May 9, 2013, resolution CFM 2.013 was published after insistent and recurrent requests from fertility clinics throughout the country to provide protocols for cases in which dilemmas with assisted reproduction occur. This resolution revoked CFM 1957/2010 and solicited input from regional medical councils and professional societies across the country for a review of the previous resolution. In accordance with the prior resolution, Article 1, Paragraph 4 confirmed that "ART should not be used for the purpose of sex selection (presence or absence of a $Y$ chromosome) or to affect any other biological feature of a future child except in cases that involve gender-related disease prevention". Article 6 directly refers to PGD and establishes two purposes for the technique's application: 1) diagnosis of genetic alterations that promote the development of diseases and 2) embryonic human leukocyte antigen (HLA) system typing to select compatible embryos for a sibling who is already affected by a disease. Discussion of other aspects of PGD continues to be limited.

\section{Discussion}

Although ART availability still varies geographically, $78 \%$ of the world's population resides in countries in which IVF services are offered. However, in reality, many factors, such as treatment costs, cultural and religious differences, travel distances, and limited awareness, prevent individuals from accessing this service. Ways in which access to this service should be funded and regulated are likely debated in all countries that provide ART. These debates are especially complex in the case of developing countries such as Brazil, where resources are sparse and competing health needs are prominent. According to the analysis by Dyer and Pennings (26) of government investment in ART in cases of scarce State resources, resources must be dedicated to areas that most effectively promote health relative to diseases and disabilities that either endanger life or significantly impair human welfare, and which may be treated with effective interventions that substantially benefit the individual.

Given the risks posed by hereditary genetic diseases, it is evident that the demand for attention cannot be ignored and that guidelines on the prevention and treatment of such cases should be prioritized. Prevention through genetic counseling can reach a larger number of individuals and is less expensive (27), although PGD for couples who wish to have children but who present specific genetic risks has proved effective in reducing the transmission of diseases that could seriously affect families and society as a whole (4).

However, to perform PGD, the woman must undergo IVF treatment, which comes with risks, side effects, and high costs. According to the American Society for Reproductive Medicine, the average cost of IVF in the United States is US $\$ 12,400$ per cycle, and an additional US $\$ 3,000-5,000$ is required to execute the PGD procedure (28). This is an important point when one considers the costs of ART to the State and the estimation of average life costs per child for congenital abnormalities, which could in some cases be prevented through the use of this technique. Estimation of 
the average life cost per child for congenital abnormalities should include, in addition to medical treatment, development services (such as physiotherapy, speech therapy, and occupational therapy), special or inclusive education, loss of productivity due to disability or death, and loss of income for the relative responsible for child care (27). These psychological and financial impacts on families with children with congenital abnormalities or hereditary diseases are considerable enough to justify investment in preventative public policies (24).

An analysis of legislative regulation on ART in Brazil shows that some advances have been achieved over time. Nevertheless, ethical and technical aspects of PGD are superficially addressed, and most of the legislation simply reproduces the CFM resolution, providing no additional directive on the regulation of $P G D$ and failing to address ethical, scientific, and legal repercussions of this selective technique. Because such legislation is typically written by physician parliamentarians, these documents present several clinical arguments which promote the notion that technical authority should prevail over beliefs and values (14).

It is worth noting that, while PGD was originally designed for families that are affected by serious or fatal hereditary genetic diseases, the method has been applied to select features that are unrelated to diseases that seriously affect the individual, thus raising ethical questions on a global scale that must be considered by society, experts, and policy makers in Brazil. Among others, examples of such cases include the selection of embryos based on histocompatibility (HLA) for the donation of tissues, the diagnosis of genetic susceptibility to disease, and fetal sex selection without medical indications.

Concerning embryo selection for HLA, in 2012 Figueira et al. (29) reported on the first successful birth in Brazil through PGD for $\beta$-thalassemia combined with the selection of an HLA-matched embryo for a sick sibling. This confirmed the application of this practice in Brazil as defined by the CFM resolution. However, the ethical issue that arises in the case of HLA embryo selection concerns motivations for conception that involve healing the eldest sibling. According to Wolf et al. (30), in cases where a disease affects the older sibling but has no hereditary basis, risks associated with IVF or embryo biopsy procedures would be imposed upon the younger child without any delivering countervailing benefit to that child, which can be particularly troubling.

Regarding the capacity of PGD to diagnose genetic susceptibility to disease, we were unable to find any specific reference in the examined documents in Brazil to diseases that begin in adulthood, such as hereditary breast cancer, and that present high risks (as opposed to a certainty) of developing. This technical indication criterion raises questions regarding how the possible benefits of PGD should be measured for the future child and adult against the known and unknown risks associated with this technology. Carrying a genetic mutation associated with a particular disease does not automatically cause the disease to develop. However, in some cases, it may be possible to establish an early prevention strategy and thus promote the discovery of a future cure (31).

The Human Genome Project and other initiatives in this area have promoted a new understanding of genetic diseases, which has been constantly changing. According to this new concept, virtually all diseases result from the combined influence of genes and one's environment; however, the effect of the genetic component can range from minor to significant. The ability to test genetic sequences associated with diseases and other hereditary characteristics is growing more sophisticated, and, according to the National Center for Biotechnology Information, genetic testing for more than 1,000 genetic diseases is either currently available or in development (4).

Hence, the legitimacy of medical practices with respect to genetic determinism should be considered of particular importance. The indication that PGD can be applied to prevent genetic disease, as noted in Resolution CFM 2013/ 2013 and several bills that are currently being analyzed by the Congress, does not define inclusion criteria on the technique's use. The use of terms such as "disease-causing genetic alteration" and "serious hereditary diseases" enables a fairly broad interpretation of this criterion.

With respect to the use of PGD for sex selection, since the first ethical standard in the CFM (CFM 1358/1992) was established in Brazil, it was clearly opposed to sex selection for preventing diseases linked to sex. A recent study assessed the perceptions of 723 Brazilian obstetrician-gynecologists on different aspects of PGD (32), and disagreement among the physicians was evident with respect to CFM resolutions: $36.4 \%$ believed that selection should always consider parental preferences, $42.6 \%$ believed that parental preferences should be considered only in specific cases, and only $17.4 \%$ disagreed with the couple's participation in sex selection.

The use of PGD for sex selection with no medical grounds has raised ethical concerns on whether this may promote sexual discrimination. According to those opposed to the use of PGD for this purpose, sex selection reflects the couple's child preference, and this may cause future frustration in family relationships if the child does not meet expectations imposed by his or her gender stereotype (33). For others, in cases where parents have an explicit preference for a certain sex, it is possible that the child and couple will benefit if gender expectations are fulfilled. However, it has been highlighted that, in cultures where there is an explicit preference for boys, such as China and India, sexual selection will reinforce existing gender roles, encouraging stereotypical behaviors such as the devaluation of women (34).

In most countries, there is no clear explanation for the choice of criteria adopted to validate different values and guiding principles on PGD regulation. Nevertheless, there is a strong correlation between the existence of moral and 
legal statutes on the embryo and the use of restrictive regulations on PGD (2). There are two major approaches to the moral and legal status of the embryo. In the first approach, the embryo is considered a human life with rights to full moral status from the moment of conception, because from conception onward a complete person may develop. This policy was adopted in Austria and Italy, where PGD is prohibited and where the embryo is entitled to complete protection under law. In the second approach, the embryo assumes the right to moral status from the moment of fertilization, but to a lesser degree than a person who has been born ("gradualist" statute) $(4,34)$. In such cases, PGD is typically permitted for medical purposes. Countries that follow this policy include the United Kingdom, Canada, France, and India (2).

Perceptions among experts on this topic in Brazil are partly elucidated in a study by Caldas et al. (32). When asked about the potential for human life to develop from a pre-embryo of six to eight cells, $23.5 \%$ did not respond to the question, demonstrating a moderate level of doubt on the issue, whereas $61.1 \%$ reported that the pre-embryo holds full potential for the development of human life. Given the presence of diverging opinions and cultural nuances within the population, discussions on the regulation of reproductive genetics technologies such as PGD will be crucial to depolarizing this debate and to knowing what Brazilians really think about this.

\section{Final considerations}

Despite recent advances in ART regulation in Brazil, no specific legislation on assisted reproduction and $P G D$

\section{References}

1. Soini S, Ibarreta D, Anastasiadou V, Ayme S, Braga S, Cornel $\mathrm{M}$, et al. The interface between assisted reproductive technologies and genetics: technical, social, ethical and legal issues. Eur J Hum Genet 2006; 14: 588-645, doi: 10.1038/ sj.ejhg.5201598.

2. Knoppers BM, Bordet S, Isasi RM. Preimplantation genetic diagnosis: an overview of socio-ethical and legal considerations. Annu Rev Genomics Hum Genet 2006; 7: 201-221, doi: 10.1146/annurev.genom.7.080505.115753.

3. Baruch S, Kaufman DJ, Hudson KL. Preimplantation genetic screening: a survey of in vitro fertilization clinics. Genet Med 2008; 10: 685-690, doi: 10.1097/GIM.0b013e31818180a1.

4. Baruch S. Preimplantation genetic diagnosis and parental preferences: Beyond deadly disease. Hous $J$ Health $L$ Pol'y 2008; 2-14.

5. Riley MF, Merrill R. Regulating reproductive genetics: A review of American Bioethics Commissions and comparison to the British Human Fertilization and Embryology Authority. J Scholarship Home, Genetics and Public Policy Center, Genetics and Public Policy Center Collection 2005.

6. Harton GL, Magli MC, Lundin K, Montag M, Lemmen J, Harper JC. ESHRE PGD Consortium/Embryology Special currently exists. Limited data on the practice of PGD in Brazil suggest inequality in terms of access, where a vulnerable proportion of the population that depends on the public health system remains excluded. These inequalities are exacerbated by a lack of specific regulation based on SUS principles and international agreements on individual reproductive rights.

In an environment where public services are not the focus of government investment and where there is limited ART regulation, several challenges emerge. Resolution CFM 2.013/13, the main official document that standardizes ethical conduct on ART in Brazil, represents an initial step toward PGD regulation, and limited discussion on ethical scientific dilemmas stemming from this selective technique continues. Thus, the safety and reliability of this method depend on individual experts, and decisions on ethical issues are often made by clinicians based on personal judgments of what is legal and ethical.

$P G D$ regulation in Brazil thus not only requires a broad discussion on governing consensus in the legislature, but public policies, practices, and regulations must also be considered as part of the national political and economic context, given the presence of social inequalities that restrict rights and preclude the exercise of citizenship.

More data on this issue are needed, as there is insufficient information available to help patients, experts, and public policy professionals understand the current state of the practice of PGD in Brazil. Thus, in the future, we propose the standardization of access to PGD, based on specific criteria whereby a consensus on principles guides regulations that integrate scientific, ethical, and public policy concerns in Brazil.
Interest Group - best practice guidelines for polar body and embryo biopsy for preimplantation genetic diagnosis/screening (PGD/PGS). Hum Reprod 2011; 26: 41-46, doi: 10.1093/ humrep/deq265.

7. Thornhill AR, Die-Smulders CE, Geraedts JP, Harper JC, Harton GL, Lavery SA, et al. ESHRE PGD Consortium 'Best practice guidelines for clinical preimplantation genetic diagnosis (PGD) and preimplantation genetic screening (PGS)'. Hum Reprod 2005; 20: 35-48, doi: 10.1093/humrep/deh579.

8. Hudson KL. Preimplantation genetic diagnosis: public policy and public attitudes. Fertil Steril 2006; 85: 1638-1645, doi: 10.1016/j.fertnstert.2006.01.014.

9. Knoppers BM, Isasi RM. Regulatory approaches to reproductive genetic testing. Hum Reprod 2004; 19: 2695-2701, doi: 10.1093/humrep/deh505.

10. Soini S. Preimplantation genetic diagnosis (PGD) in Europe: diversity of legislation a challenge to the community and its citizens. Med Law 2007; 26: 309-323.

11. Aarden E, Van Hoyweghen I, Vos R, Horstman K. Providing preimplantation genetic diagnosis in the United Kingdom, The Netherlands and Germany: a comparative in-depth analysis of health-care access. Hum Reprod 2009; 24: 1542-1547, 
doi: 10.1093/humrep/dep054.

12. Franklin S, Roberts C. Born and made an ethnography of preimplantation genetic diagnosis. In: Anonymous, Information series. Princeton: Princeton University Press; 2006.

13. Sequeira ALT. Potencialidades e limites para o desenvolvimento de uma política de atenção em reprodução humana assistida no SUS in Saúde da Criança e da Mulher. Instituto Fernandes Figueira, Fiocruz: Rio de Janeiro: 2011.

14. Correa MC, Loyola M.A. Reprodução e bioética. A regulação da reprodução assitida no Brasil. Caderno CRH 2005; 18 : 103-112.

15. Bardin L. Análise de conteúdo. Edições 70 - Reimpressão 223.; 2007.

16. Alfano B. Reprodução e biopolítica: infertilidades e práticas de saúde em um serviço público no Rio de Janeiro in PósGraduação em Saúde Coletiva. Rio de Janeiro: Universidade do Estado do Rio de Janeiro; 2009.

17. Brasil. Lei Federal No. 9.263, de 12 de janeiro de 1996. Brasília: Diário Oficial da União; 1996.

18. Ministerio da Saúde. Política Nacional de Atenção Integral à Saúde da Mulher: Princípios e Diretrizes. Brasília: SAS Departamento de Ações Programáticas Estratégicas, Brasil; 2011.

19. Ministerio da Saúde. Direitos sexuais e direitos reprodutivos. Uma prioridade do governo. Série A. Normas e Manuais Técnicos. Brasília: Série Direitos Sexuais e Direitos Reprodutivos: Caderno No. 1; 2004.

20. Ministério da Saúde Gabinete do Ministro. Brasil, Política Nacional de Atenção Integral em Genética Clínica. Portaria No. 81/GM. Brasília: Diário Oficial da União República Federativa do Brasil; 2009.

21. Secretaria Especial de Políticas para as Mulheres. Instrumentos Internacionais de Direitos das Mulheres. Brasília: Presidência da República (série documentos); 2006.

22. Makuch MY, Simonia de Padua K, Petta CA, Duarte Osis MJ, Bahamondes L. Inequitable access to assisted reproductive technology for the low-income Brazilian population: a qualitative study. Hum Reprod 2011; 26: 2054-2060, doi: 10.1093/ humrep/der158.

23. Makuch MY, Petta CA, Osis MJ, Bahamondes L. Low priority level for infertility services within the public health sector: a Brazilian case study. Hum Reprod 2010; 25: 430-435, doi: 10.1093/humrep/dep405.

24. Paskulin GA. Casuística e caracterização das patologias hereditárias em um hospital pediátrico. Porto Alegre: Universidade Federal do Rio Grande do Sul; 1989.

25. Ministério da Saúde. Resolução Normativa No. 211 de 11 de janeiro de 2010. Brasília: Agência Nacional de Saúde Suplementar; 2010.

26. Dyer SJ, Pennings G. Considerations regarding government funding of assisted reproductive techniques in low-resource settings, in social aspects of accessible infertility care in developing countries. Monograph. Wetteren, Belgium: Facts, Views \& Vision in Obgyn; 2010.

27. Horovitz DDG. Atenção aos defeitos congênitos no Brasil: propostas para estruturação e integração da abordagem no sistema de saúde in Pós Graduação em Saúde Coletiva. Rio de Janeiro: Universidade do Estado do Rio de Janeiro; 2003.

28. Collins J. An international survey of the health economics of IVF and ICSI. Hum Reprod Update 2002; 8: 265-277, doi: 10.1093/humupd/8.3.265

29. Figueira RC, Setti AS, Cortezzi SS, Martinhago CD, Braga $\mathrm{DP}$, laconelli $\mathrm{A} \mathrm{Jr}$, et al. Preimplantation diagnosis for betathalassemia combined with HLA matching: first "savior sibling" is born after embryo selection in Brazil. J Assist Reprod Genet 2012; 29: 1305-1309, doi: 10.1007/s10815-012-9862-3.

30. Wolf SM, Kahn JP, Wagner JE. Using preimplantation genetic diagnosis to create a stem cell donor: issues, guidelines \& limits. J Law Med Ethics 2003; 31: 327-339, doi: 10.1111/ j.1748-720X.2003.tb00097.x.

31. Spriggs M. Genetically selected baby free of inherited predisposition to early-onset Alzheimer's disease. J Med Ethics 2002; 28: 290, doi: 10.1136/jme.28.5.290.

32. Caldas GH, Caldas E, Araujo ED, Bonetti TC, Leal CB, Costa AM. Opinions concerning pre-implantation genetic diagnosis and sex selection among gynecologist-obstetricians in Brazil. Eur J Obstet Gynecol Reprod Biol 2010; 148: 158-162, doi: 10.1016/j.ejogrb.2009.10.023.

33. Alam N. Open Letter on Sex selection to fertility industry trade group. Center for Genetics and Society; 2002.

34. Daar JF. ART and the search for perfectionism: on selecting gender, genes, and gametes. J Gender Race Just 2005; 9: 241-272. 